\title{
Graphene Oxide: The New Membrane Material
}

\author{
R. K. Joshi ${ }^{1 \#}$, S. Alwarappan ${ }^{2}$, V. Sahajwalla ${ }^{1}$, M. Yoshimura ${ }^{3}$ and Y. Nisina ${ }^{4}$ \\ ${ }^{1}$ Centre for Sustainable Materials Research and Technology, School of Materials Science and \\ Engineering, University of New South Wales, NSW 2052, Australia \\ ${ }^{2}$ CSIR-Central Electrochemical Research Institute, Karaikudi, Tamilnadu, India \\ ${ }^{3}$ Surface Science Laboratory, Toyota Technological Institute, Nagoya, Japan \\ ${ }^{4}$ Research Core for Interdisciplinary Sciences, Okayama University, Okayama, Japan
}

\#Email: r.joshi@unsw.edu.au (RKJ); salwarap@gmail.com (SA); nisina-y@cc.okayama-u.ac.jp(YN)

A perfect molecular level separating unit for any kind of species to be filtered is on very high demand. In recent years, graphene oxide has emerged as an important material which can filter ions and molecules with high precision. This is an emerging field of research which has drawn extensive attention after the work by Nair et al (Science vol. 335, 2012, p442). Following this work, various research groups started working in this area in last three years. Herein, we briefly review the recent development on graphene oxide membranes. This review is a summary of some very important results and contribution made so far in this emerging research field. Moreover, in this review, we discuss some very important recently developed mechanisms and models to understand the transport through the membranes. This review begins with a basic background on membrane technology.

\section{Membranes}

A membrane is considered as a barrier with an ability to allow the passage of certain species while blocks other depending on characteristics of the membrane and species to be filtered. Membrane technology is a rapidly

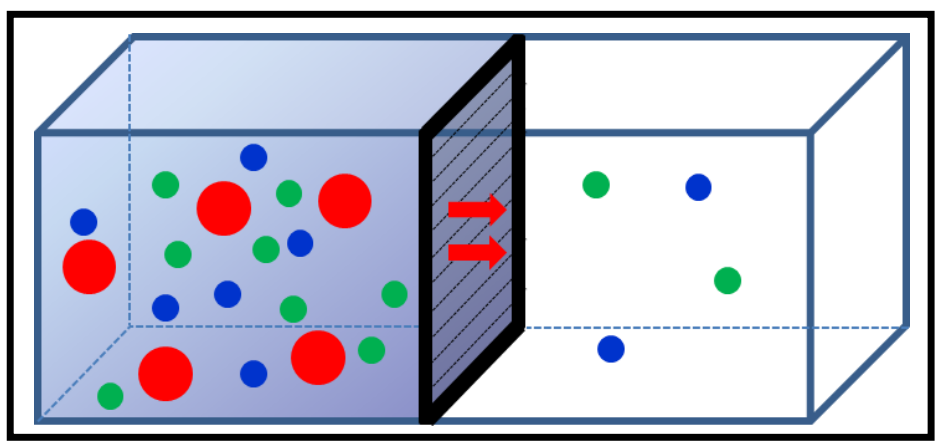

Figure 1. Schematic representing a membrane system growing research area with several real time applications such as desalination and water 
purification. Scientists and engineers have been working towards the development of this technology for a more cost-effective and a precise membrane. Indeed, there are already some well-established membranes, otherwise, how is it possible to have clean drinking water and to remove chemical contaminants? However, their accuracy, ability, and cost effectiveness vary depending on the membrane types. Till now, it is a difficult task to construct atomic scale capillaries in membranes that will perfectly allow the separation of the species from the solutions depending on their molecular and ionic size.

Traditionally, membranes have been classified into two types, as polymeric membranes [1-5] and inorganic membranes [6-13]. However, it is hard to choose one amongst them as a preferred membrane based on their application, because each type of the membrane has its own advantages and disadvantages. For example, the polymeric membranes have high perm-selectivity and fast permeation, but they have limited resistance to temperature, solvents and corrosive environments. Inorganic membranes, mainly made of ceramics or metals, have superior thermal, mechanical and structural strength. Such membranes, however, show extremely high selectivity but have limited permeability which often prohibits their wide scale applications. On the other hand, micro porous silica membranes which are also inorganic membranes have been used for molecular sieving applications in the past. However, precise control of pore size in sub-nanometer range for size dependent molecular filtration is an issue which has not been totally resolved yet for these membranes. These issues have been sorted out to some extent in zeolite membranes which are another type of inorganic membranes.

Zeolites with well-defined pore system in molecular dimensions are stable at high temperatures with hydrophilic and organophilic properties [14-19]. Due to these characteristics, zeolite membranes could have been excellent filters in molecular scale but these membranes are associated with features such as solid acidity, ion exchange capability, adsorption or release capability, and catalytic nature of zeolite often limit their application. These characteristics might be advantageous for certain applications but prohibit zeolite membranes from the applications where the membrane is required to act as a neutral filter. In other words, zeolite often catalyzes the filtration process for certain species. Other aspects which we believe that will dilute their potential applicability are the possible existence of pores with different sizes in membranes (zeolite pores with sub-nanomater size as well as the inter-crystal micron size pores). In order to overcome this issue, the zeolite 
crystals should be grown in an interlocking fashion so that the transport can only occur through the zeolite pores. This adds up few more steps in the synthesis procedure of precise molecular sieves.

In the last decade, carbon nanotube (CNT) membranes attracted huge attention for possible filtration application [20-30]. Studies related to CNT membranes have certainly provided a breakthrough towards understanding the science associated with filtration mechanism. However, their application was limited due to the difficulties associated with making their inner diameter in atomic range which is also accompanied by a complex process to construct CNT membranes. Nevertheless, successful efforts have been made in the past to develop gold nanotubes with their inner diameter approximately $0.6 \mathrm{~nm}$ [31]. Template based electrochemical growth technique was used to synthesize gold nanotubes for this purpose. These nanotubes were unique due to their inner diameter in the molecular level but could not get considerable attention for practical application due to the difficulties associated with the re-production of nanotube using electrochemical growth.

After the discovery of graphene in 2004 , this material has been exploited for various applications and it has demonstrated outstanding properties; even as par the best in every application it is tested for. There are some reports showing the membrane properties of pure graphene [32-36]. Pure graphene membrane without pores is highly impermeable due to the closely packed arrangement of carbon atoms in the lattice. In addition, the pielectron cloud repels all the molecules. Such a type of impermeable graphene membrane can find potential application in future for the synthesis of gel, impermeable capsule and sealed cages. It is still a challenge to use pure graphene membrane as molecular and ionic sieves in normal condition. However, research works are in progress in this direction to achieve a considerable water flux using graphene membrane. Graphene, being a 2D ultrathin planar material with very high mechanical strength, it necessitates only a very low pressure requirements to enable ultrafast liquid-phase and gas-phase separation process.

Recently, Graphene oxide (GO) has emerged as excellent membrane material. In the year 2012 Nair et al, demonstrated that GO membrane allows un-impeded permeation of water whereas it blocks everything else in the vapor form [37]. However, their work does not ruled out the joint propagation of organic molecules dissolved in water through GO membrane. The ease in making atomically thin GO layers in the form of membrane provides an edge over other membranes for their practical applications. Graphene, in general, does 
not allow anything to pass through. Graphene oxide (GO) is continuously demonstrating its excellent membrane characteristics and offer huge potential for real applications. In the next sections we are presenting application of graphene oxide in gaseous and liquid mediums.

GO Membranes for Gas Separation: Nair et al reported graphene oxide based membrane for the first time [37]. In their work, it has been clearly demonstrated that the graphene oxide membrane blocks everything expects water vapour. This was a maiden effort to utilise a pure graphene oxide membrane for filtration. According to Nair el al., the

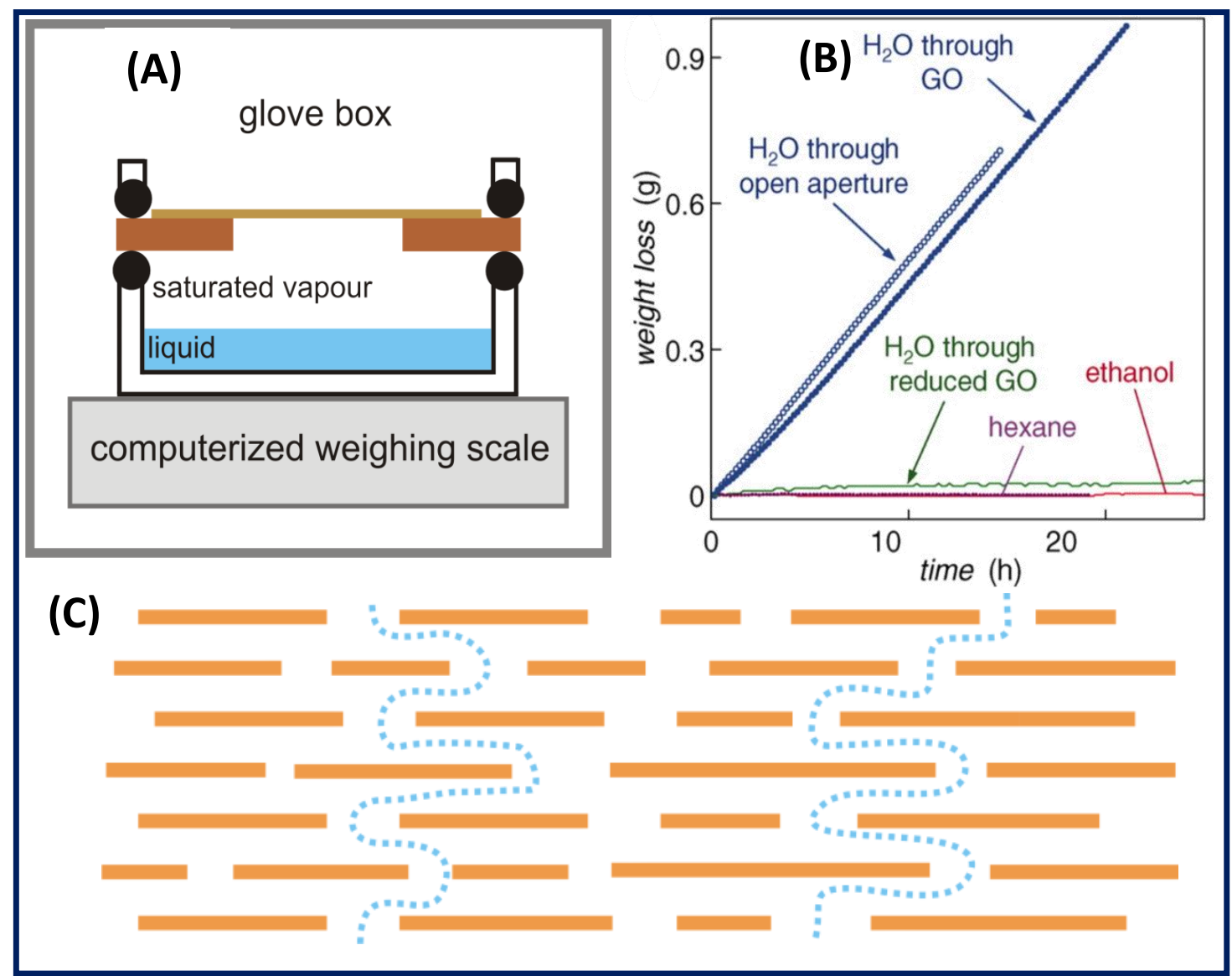

Figure 2: a) Schematic of an experimental set-up to assess the permeation of GO layers.

b) Plot showing the results of vapour permeation, weight loss of the container filled with target solution over a period of time. c) Schematic representing the possible water transport mechanism. Figure re-used with permission from [37].

membranes only allow water vapour to pass through and completely block the vapours of ethanol and other alcohol molecules. In their work, GO was prepared by Hummers Method [38] and then through vigorous ultra-sonication and centrifugation, graphene oxide (GO) 
sheets with an average size of 1 micron were prepared [39-44]. In order to make GO membranes, the GO solution can be vacuum filtered in a conventional way on an alumina template support. Alternatively, GO membrane can also be obtained by spraying GO solution on a solid surface and then etching away the solid part as required. In order to evaluate the permeation possibility, authors have employed a weight loss measurements of the container filled with alcohol (initially) and properly sealed with GO membrane shown in the Figure 2(a). Results indicated that there was no noticeable change in the weight of the container when it was filled with ethanol. However, a linear time dependent weight loss was noticed when the container was filled with water as shown in Figure 2(b). In their experiment, they noticed no variation in the differential pressure for the container filled with various gases such as $\mathrm{He}, \mathrm{H}_{2}, \mathrm{~N}_{2}$ and $\mathrm{Ar}$ under a small overpressure. From the results, they concluded that no gas can pass through the membrane. Figure 2 (c) is the schematic for possible watervapor transport method through GO membrane. Nair et al explains that the GO laminates consists of crystallites stacked on top of each other and the hydroxyl epoxy

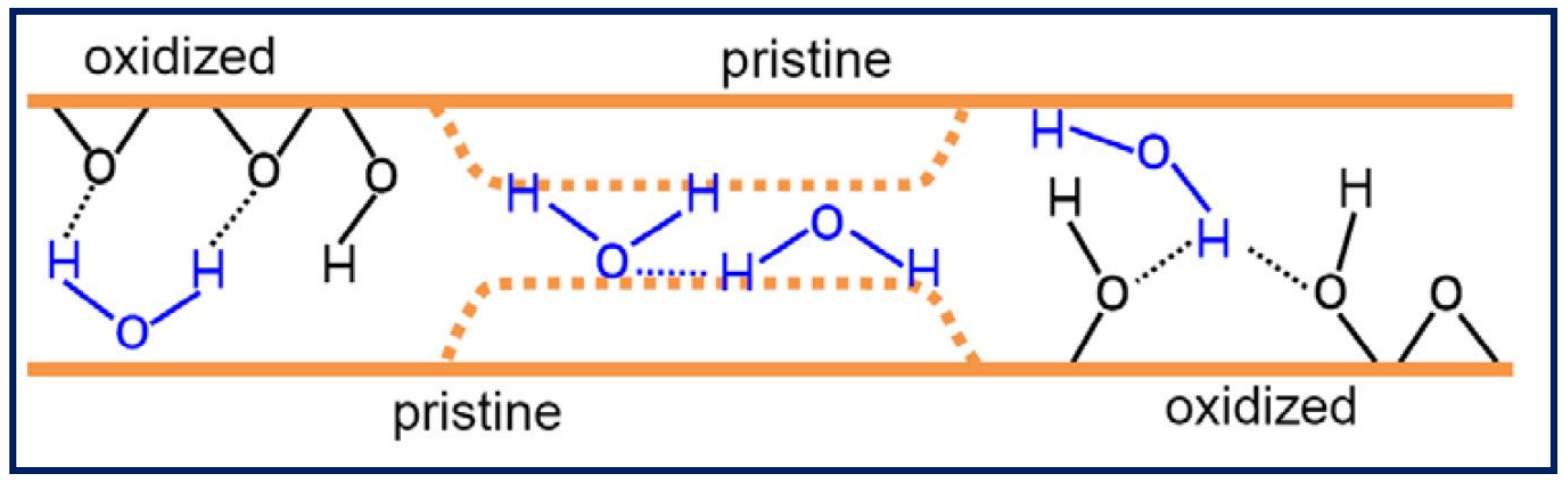

Figure 3. Schematic model of the nano capillaries in GO films. Monolayer water can move through the capillaries when they wide open however in the low humidity the capillaries becomes narrower (shown by dashed line) and as a result there is no sufficient space between the capillaries to accommodate the water molecule. Figure reproduced with permission from [37].

groups attached to the graphene sheets offers spacing between the membranes. According to their model and explanation, the pristine graphene capillaries are wide open to accommodate the water molecule and the capillaries becomes narrow in low humidity, which does not provide enough Vander-Waals distance to accommodate water molecules and this mechanism is shown in the Figure 3. Following this work, this area got immense attention and in another few years several research works has been reported. Kim et al. demonstrated that graphene oxide sheets can be appropriately engineered gas separation 
applications [44]. In their work, they have investigated the gas permeation behaviour of GO membranes and demonstrated the selective gas diffusion by controlling the membrane parameters.

In order to design good quality membranes, Kim et al., have employed two different methods for GO preparation. In the first method, they obtained several layered GO membranes by contacting the support membrane surface to the air-liquid interface of a GO solution followed by spin coating. In the second method, they employed only spin coating to obtain thin GO membrane. Based on their result, they concluded that the gas transport mechanisms associated with the membranes obtained through these two different methods
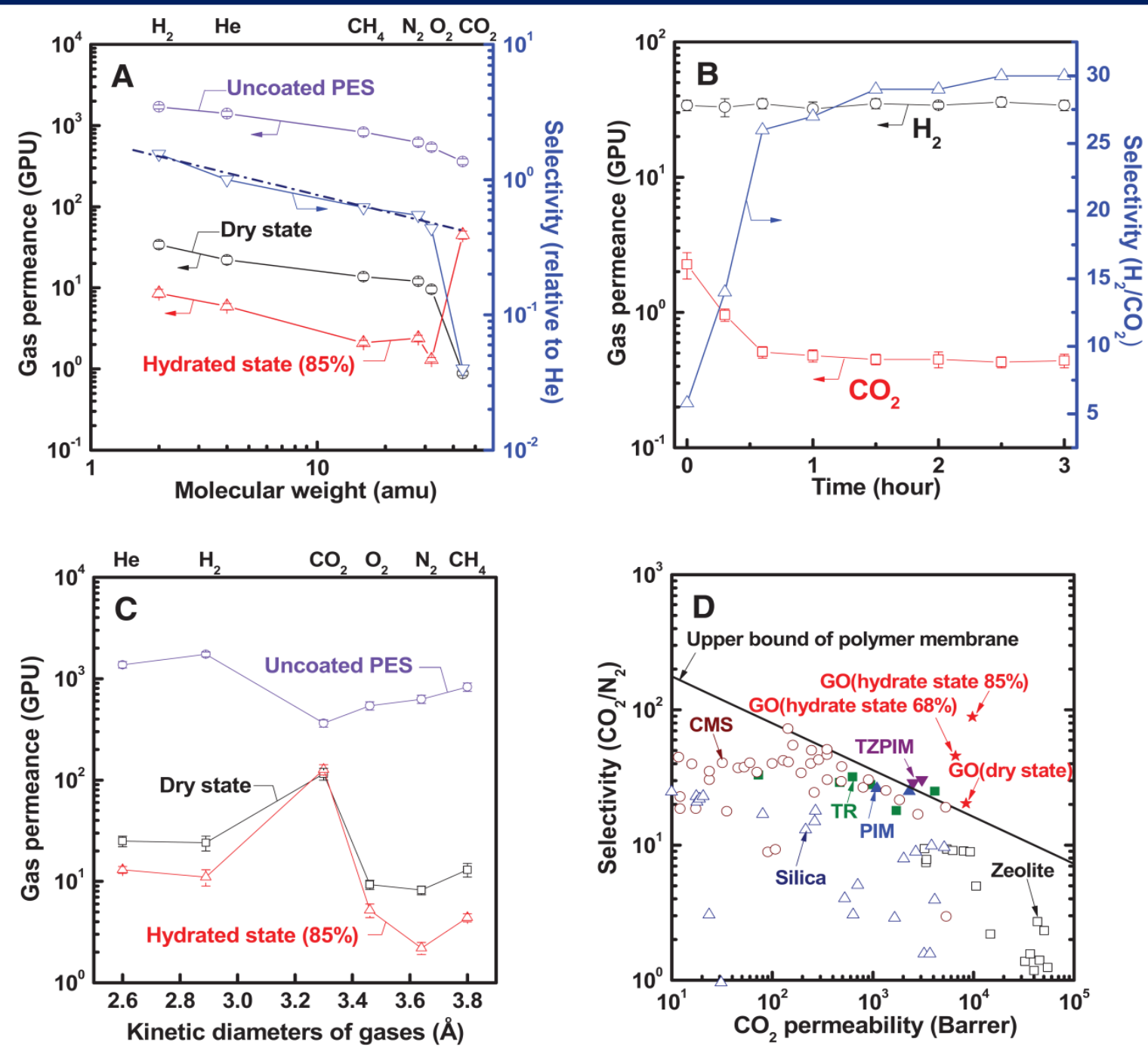

Figure 4. A) Permeation of gases $\left(\mathrm{H}_{2}, \mathrm{He}, \mathrm{CH}_{4}, \mathrm{~N}_{2}, \mathrm{O}_{2}\right.$ and $\mathrm{CO}$ as function of Molecular Weight under different conditions i.e dry and hydrated state. B) Gas permeation with time (h) for $\mathrm{H}_{2}$ and $\mathrm{CO}_{2}$, and also the selectivity for $\mathrm{H}_{2}$ and $\mathrm{CO}_{2}$. C) Variation of gas permeation with the kinetic diameter of the gases under dry and hydrated state. D) Variation of $\mathrm{CO}_{2} / \mathrm{N}_{2}$ selectivity with $\mathrm{CO}_{2}$ permeability; it also compares the GO membrane properties with well known membrane of silica and zeolite. Figure reproduced with permission from [44]. 
vary. In their work, they have witnessed molecular weight dependence of the gas permeation through the GO membrane. Figure 4 depicts the gas permeation through ultrathin GO membranes and in that work Kim et al [44] observed that the gas permeation decreases upon increasing the humidity of the feed. In other words, the condensed water molecule affects the transport of gases though the pores in the membrane. Furthermore, the authors observed a gas permeation trend which varies in the following order $\mathrm{CO}_{2}>\mathrm{H}_{2}>\mathrm{He}>\mathrm{CH}_{4}>\mathrm{O}_{2}>\mathrm{N}_{2}$ at room temperature. Their study of gas transport is certainly one step ahead in the field of membrane technology based on graphene oxide.

Zhang et al [45] demonstrated the improved hydrophilicity, permeability and antifouling performances of Graphene-Oxide ultra-filtration membranes by incorporating oxidized MWCNTs and PVDF. The researchers compared the hydrophilicity, permeability and antifouling performances of PVDF-OMWCNTs, PVDF-GO, PVDF-GO-OMWCNTs. Briefly, all these materials were synthesized by the combination of solution blending route and phase inversion method. Of these various membranes that have been synthesized the contact angle is least for PVDF-GO-OMWCNTs indicating the improved hydrophilicity of this membrane over other membranes. Further, it was reported, of all these membranes PVDFGO-OMWCNTs membrane exhibited a greater permeation flux of about $240 \%$ and an increase in BSA rejection rate $14.23 \%$ and also upon comparison with its pristine counter parts.

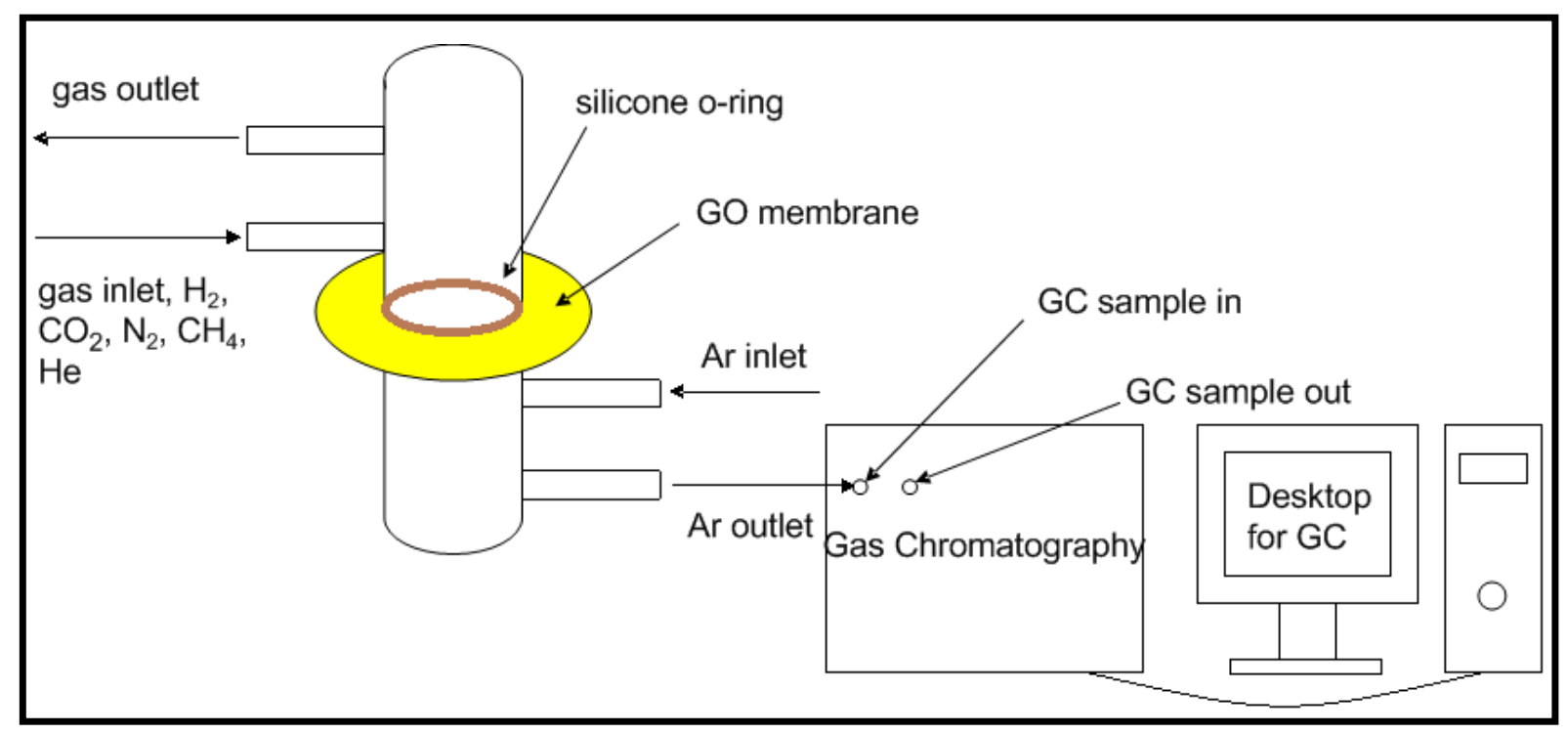

Figure 5: Schematic of experimental set-up used by Li et al for the permeation measurement. Figure adopted from the supporting information of [46] with permission. 
In another work, Li et al. studied the hydrogen separation using ultrathin GO membranes [46] and their experimental set-up is shown in Figure 5. In their work, the authors observed selectivity of 3400 for $\mathrm{H}_{2} / \mathrm{CO}_{2}$ mixture and 900 for $\mathrm{H}_{2} / \mathrm{N}_{2}$ mixtures. An important point in this study is that the permeation is through the structural defects on GO. Figure 6 shows the permeation results as the function of kinetic diameter of gas molecules and membrane thickness. Authors observed that $\mathrm{H}_{2}$ with a kinetic diameter of $0.289 \mathrm{~nm}$ permeates 300 times faster than $\mathrm{CO}_{2}$, which has kinetic diameter of $0.33 \mathrm{~nm}$. Results, suggested that the average size of pores vary between 0.289 to $0.33 \mathrm{~nm}$. Based on their results, authors speculate that the transport pathway for gas molecules is the structural defect rather than the interlayer spacing proposed by Nair et al for water vapour transport. However, when they employed GO for water permeation test, Li et al results agree well with Nair et al. as the water permeation decreased for reduced GO membrane. This is due to the narrowing of interlayer spacing in reduced GO. When they performed a single gas permeation test using $18 \mathrm{~nm} \mathrm{GO}$ membrane, authors observed no gas permeation changes and suggested that the interlayer spacing were not channels for transport but structural defects with GO flakes are the pathway for transport.

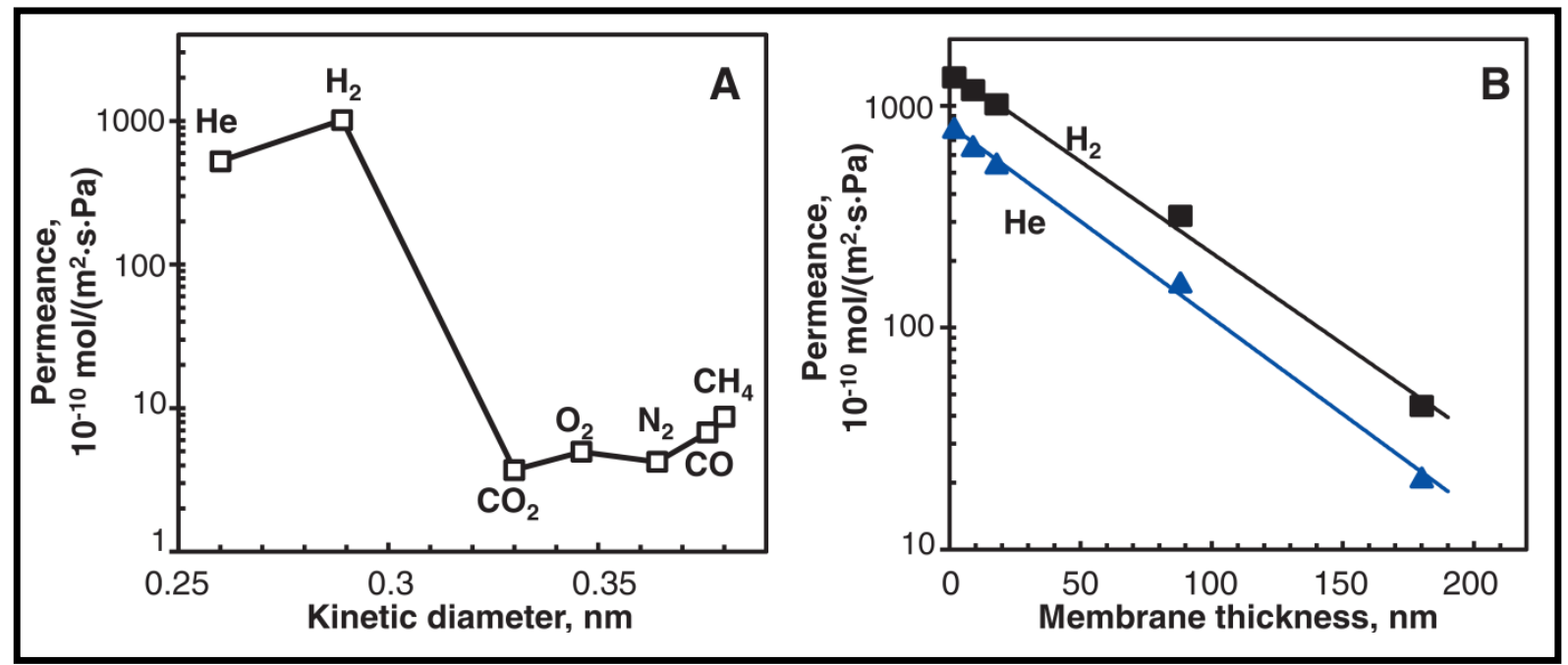

Figure 6. Results of gas permeation through a GO membrane at $20^{\circ} \mathrm{C}$. a) Variation of permeance with kinetic diameter of gas molecules. b) variation of permeance of $\mathrm{H}_{2}$ and $\mathrm{He}$ with membrane thinness. Figure reproduced with permission from [46]

Reports by Nair et al [37], Kim et al [44] and Li et al [46] on gas and vapour transport through GO membrane has been considered as very important contributions to the science and technology of membranes. Further, in another important work, Schrier [47] 
demonstrated the usefulness of a two dimensional hydrocarbon polymer called Porous Graphene E-Stilbene 1 (PG-ES1) in order to separate $\mathrm{CO}_{2}$ from $\mathrm{N}_{2}, \mathrm{O}_{2}$ and $\mathrm{CH}_{4}$. Based on the molecular dynamics simulations, in the same work, Schrier [47] evidenced that the two dimensional PG-ES1 employed adopted a combination of surface adsorption as well as narrow pores to separate $\mathrm{CO}_{2}$ from the other gases mixture. Moreover, the $\mathrm{CO}_{2}$ permeance, $\mathrm{CO}_{2} / \mathrm{N}_{2}$ selectivity and $\mathrm{CO}_{2} / \mathrm{CH}_{4}$ selectivity for the PG-ES1 employed in this work was found to be $3 \times 10^{5} \mathrm{GPU}, 60$ and 500 respectively. These observed values were found to be the best of all other values reported and thereby the material employed in this work has potential applications in $\mathrm{CO}_{2}$ capture and upgrading biogenic methane.

\section{GO Membrane as Ionic and Molecular Sieve in Solution}

Reports discussed in Section 2 have shown the potential of GO membrane as a future material for filtration. Work reported by Nair et al was immediately followed by a demonstration of selective ion penetration through GO membrane by Sun et al [48]. Sun et al reported that sodium salts permeate freely through the membrane whereas the salts of
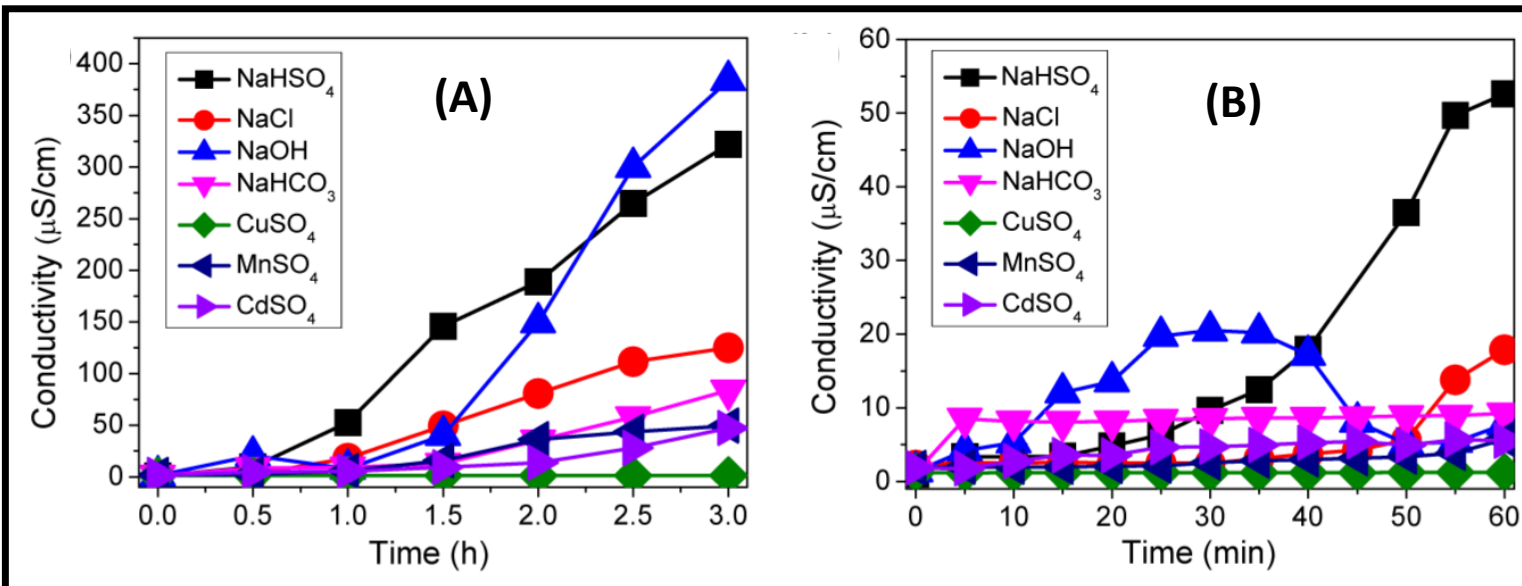

Figure 7. A) Change of conductivity (as permeation parameter) with time for various salts. B) The plot shows the initial process of the salt transport through $\mathrm{GO}$ membrane. Figure re-used with permission from [48].

heavy metals take a longer time to pass through. Their membrane blocks the copper salts and organic contaminants. The reason for the observed behaviour is that the metal salts permeate through nano capillaries in GO membrane, however, in the case of heavy metal ions the coordination between them and GO membranes block the permeation. Figure 7 shows the variation of permeation with time in the form of change in conductivity. The mechanism of permeation is completely based on the theory proposed by Nair et al [37]. 
According to them, the high capillary pressure leads to the friction less flow of water and the distance available between the layers is responsible for the water flow. Therefore, when the distance is higher, ions in their hydrated form can pass through the membrane channels. So, larger species cannot pass while smaller ones move through the capillaries. However, it is interesting to note that the permeation ability reported by Sun et al [48] is independent of the size of the tested species. In their report, the permeation ability follows the trend $\mathrm{Na}>\mathrm{Mn}>\mathrm{Cd}$, but the size variation has a trend $\mathrm{Mn}>\mathrm{Cd}>\mathrm{Cu}>\mathrm{Na}$. With this, Sun et al [48] concluded that the electrostatic interaction between the functional group in $\mathrm{GO}$ and hydrated ions are responsible for this selective (however, size independent) permeation. Further, Sun et al [48] also studied the barrier separation properties and demonstrated that sodium salts can be separated from copper salts and also from the organic molecules using
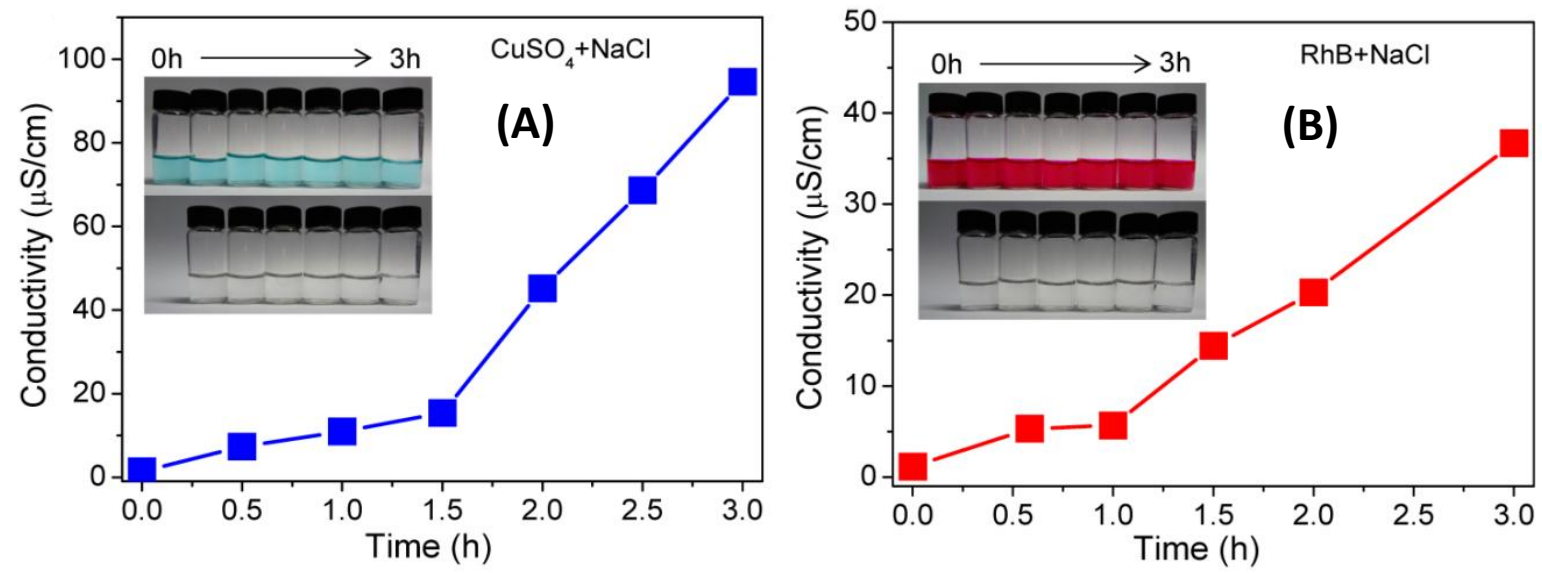

Figure 8. Barrier separations study. A) Permeation process corresponding to the mixture of $\mathrm{NaCl}+\mathrm{CuSO}_{4}$ trough $\mathrm{GO}$ membrane where the insert shows the photograph of feed mixture and permeate. B) Same process for the mixture of $\mathrm{NaCl}$ and RhB. Figure re-used with permission from GO membrane. Figure 8 is the representative barrier separation behaviour. The inset in Figure 8 shows the photographs of the feed and permeates with time. In the first case of $\mathrm{NaCl}+\mathrm{CuSO}_{4}$, feed has the colour of $\mathrm{CuSO}_{4}$ which does not affect the colour of filtrate due to the separation. Similarly, the colour of RhB does not affect the colour of permeate since RhB does not pass through the membrane. As discussed in the original article [48], the conductivity change is slow in initial stage followed by a rapid increase. 
The observed effect is due to the wet condition of GO membrane to allow any ions to pass through. Once the membrane is wet, the capillaries become wider to accommodate hydrated $\mathrm{Na}^{+}$ions. The process of narrowing and widening of the nanocapilaries was introduced by Nair et al.

Huang et al [49] have studied the filtration properties of GO nanochannels. They have tuned the membrane properties by tuning $\mathrm{pH}$, salt concentration and pressure. Hung et al [49] observed $85 \%$ of rejection rate for Evans Blue (EB) and noticed a water flux of $71 \mathrm{~L} \mathrm{~m}^{-2} \mathrm{~h}^{-1}$ bar $^{-1}$ for some of their membranes.

Figure $9(\mathrm{~A})$ depicts how the flux rate decreases abruptly with a slight increase in $\mathrm{NaCl}$ concentration. According to their explanation, the nanochannel network in membrane, which is actually the inter sheet distance blocks some molecules. Furthermore, these nanochannels are biased for one type of charges thereby making the pores dependent on the charge of testing ion. Authors have concluded a charge type dependence of filtration process of $\mathrm{GO}$ membrane by doing experiment with varied concentration at a fixed pressure. It is understood that the additional electrolyte supress the channel width and hence the filtration. It can be concluded from their work that the
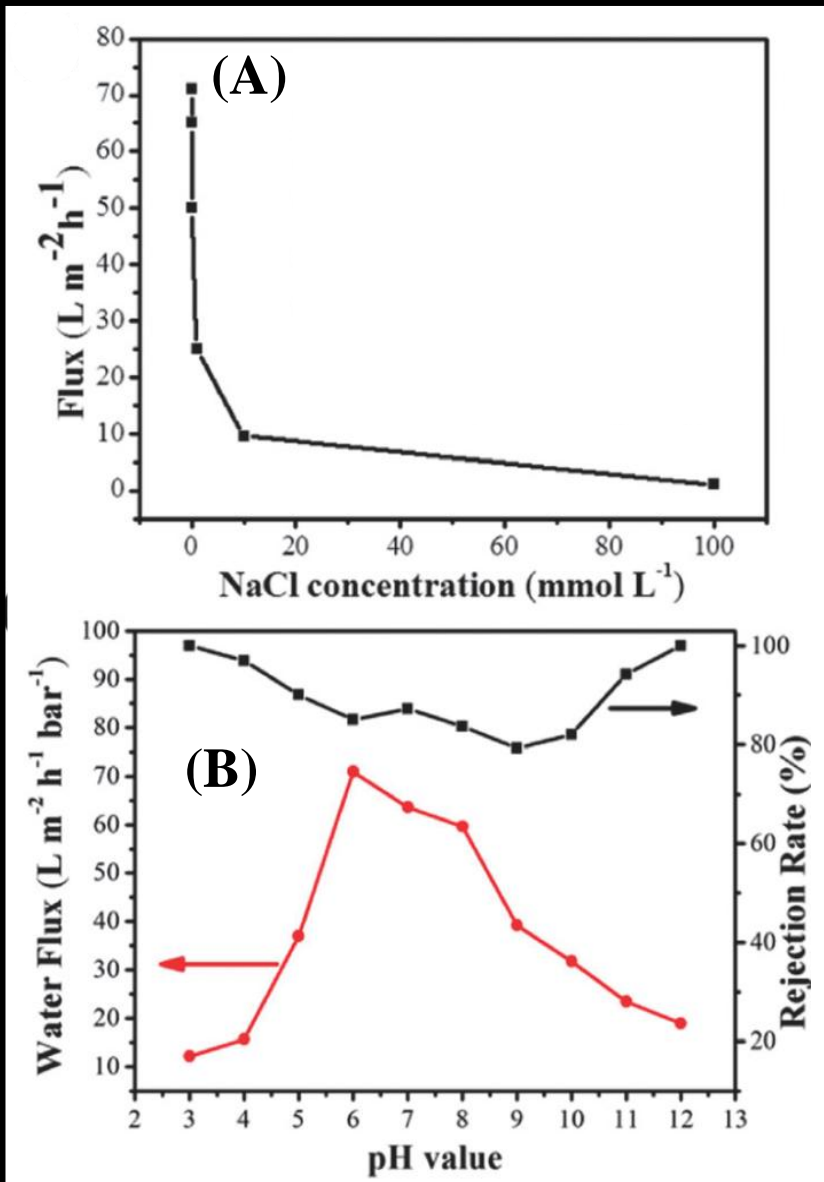

Figure 9. A) Plot showing the variation of flux with $\mathrm{NaCl}$ concentration. B) Plots show the variation of water flux and rejection ratio with $\mathrm{pH}$ of the solution. Figure re-used from [49] with permission.

membrane filtration depends on type and concentration of charge near GO membrane. This result was backed by solution $\mathrm{pH}$ dependence of membrane properties (Figure 9B). Due to the protonation of carboxylic acid the electrostatic repulsion between GO sheets weakens at lower $\mathrm{pH}$.As a consequence of this the flux rate decreases and the rejection of EB molecules takes place. 
$\mathrm{Hu}$ and $\mathrm{Mi}[50]$ have used GO membrane for separation in liquid medium.

In their work, GO membrane was

made a layer-by-layer deposition of GO nanosheets linked by $1,3,5$ benzenetricarbonyl trichloride. Authors measured the water flux and rejection for the GO membranes using a dead-end membrane filtration technique. Figure 10(A), (B), (C) shows some of their results. They observed that the water flux does not show a monotonic decrease with increase in the number of $\mathrm{GO}$ layers.Authors have tested the separation performance as function of number of GO layers for $\mathrm{NaCl}, \mathrm{Na}_{2} \mathrm{SO}_{4}$ and two organic dyes. As we see in the plots the rejection rate for salts depend on the number of layers. These membranes show a rejection rate of over $90 \%$ for rhodamine WT (R-WT) dye and around $50 \%$ for the MBdye. Authors conclude that the higher rejection for R-WT is due size exclusion effect for higher molecular weight and also because of the negative charge of GO. As discussed in the original article, the presence of carboxylic groups enhances the rejection of negatively charged R-WT.

Figure 10 (c) supports their assumption of charge effect on rejection rate of species. Authors observed a decrease of rejection rate with increasing concentration of salts for a membrane with 15 GO layers (which they explained on the basis of varied Debye length for different

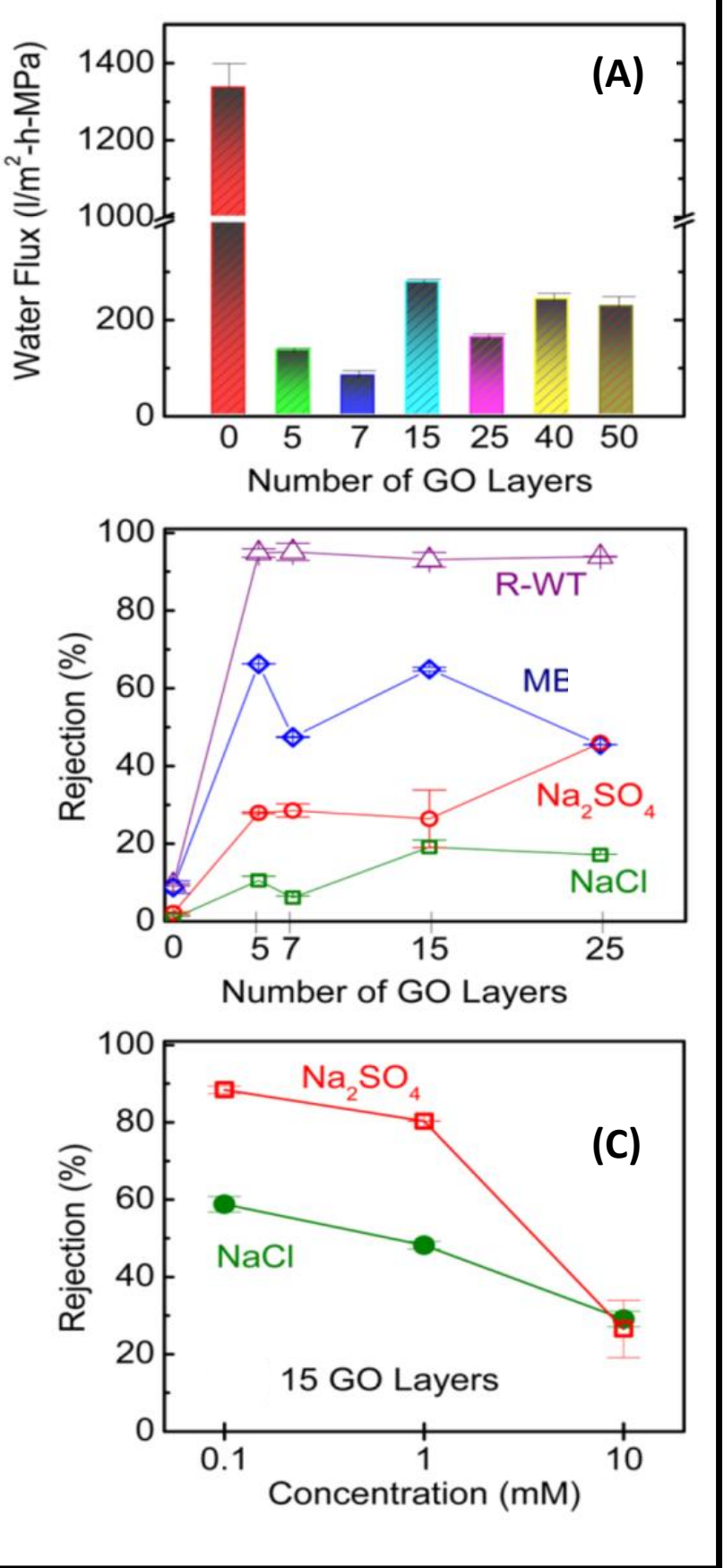

Figure 10.A) Performance of GO membrane in terms of water flux with varied number of GO layers. B) Variation of rejection rate for salts and dyes with number of $\mathrm{GO}$ layers. C) Rejection rate as function of salt concentration. Figure adopted from [50] with permission. 
concentration of salts). Variation in Debye also length affects the electrostatic repulsion between the ions and charged membrane and hence the permeation ability.

Huang et al [51] recently observed ultrafast water flow using GO membrane through the nanochannels with a size distribution of 3-5 $\mathrm{nm}$. The GO membranes studied by the authors have nanostrand channels. Schematic of the preparation of such type of modified membrane is shown in Figure 11. Authors have used positively charged copper hydroxide nanostrands and negatively charged GO sheets on a porous support. We recommend the readers to go through the original article for the complete synthesis procedure. Further to test the permeation ability authors have selected various species for their permeation through these membranes. Table 1 taken from the original article shows the summary of the results obtained by Huang et al [51] It appears that their membranes have $100 \%$ rejection only form Au nanoparticles of $5 \mathrm{~nm}$ diameter and slightly less for cytochrome $\mathrm{c}$. In

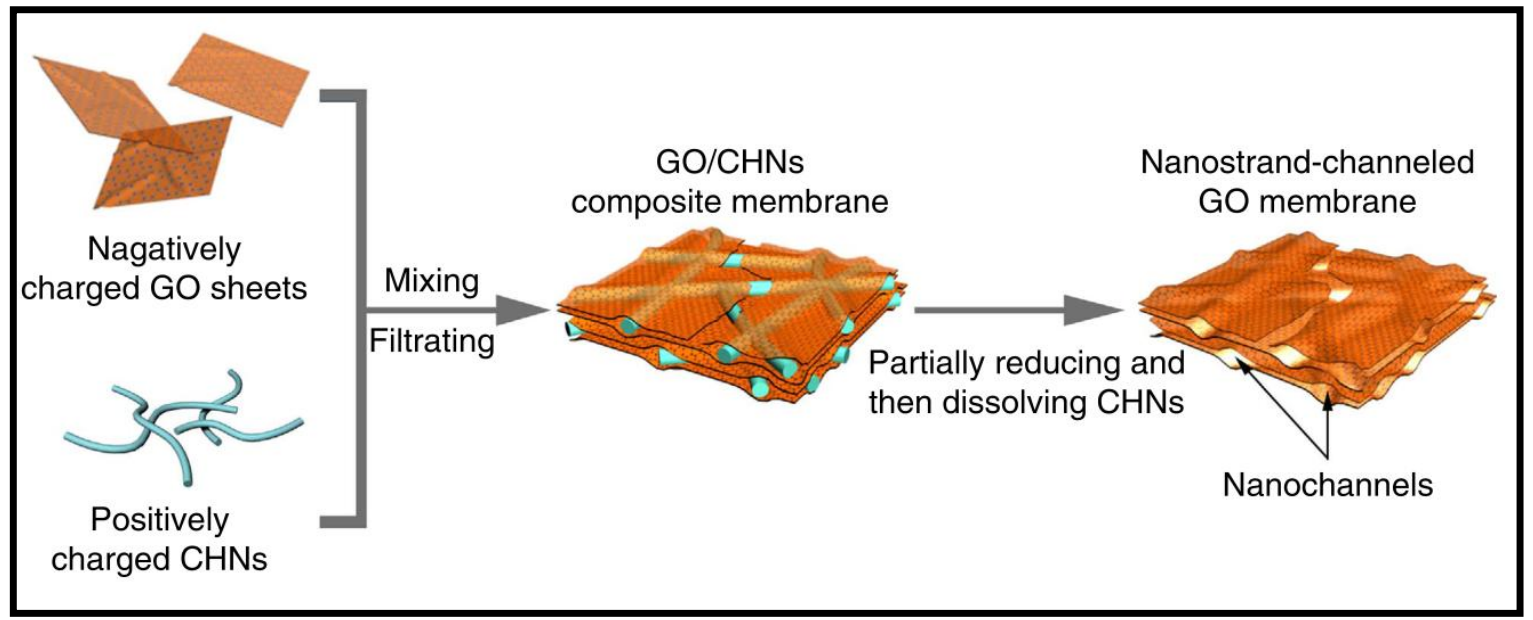

Figure 11. Schematic shows the various steps of synthesising nanostrand-channeled GO membrane. Figure adopted from [51] with permission.

their study the smallest ion tested was $\mathrm{K}_{3} \mathrm{FeCN}_{6}$, which is close to $1 \mathrm{~nm}$. Further the authors reported that their membranes show a favourable behaviour for the species with one type charge. They observed that the negatively charge GO membrane can trap the positively charged species. 


\begin{tabular}{|c|c|c|c|c|c|c|}
\hline \multicolumn{6}{|l|}{ Table 1} & \multirow[b]{2}{*}{$\begin{array}{l}\text { Rejection } \\
\text { (\%) }\end{array}$} \\
\hline $\begin{array}{l}\text { Size-specific } \\
\text { molecule or } \\
\text { ion }\end{array}$ & $\begin{array}{l}\mathrm{MW}(\mathrm{g} \\
\left.\mathrm{mol}^{-1}\right)\end{array}$ & Concentration & $\begin{array}{l}\text { Size in } \mathrm{nm} \\
\text { (width } \\
\text { diameter) }\end{array}$ & Analyte & $\begin{array}{l}\text { Permeance } \\
\left(\mathrm{Im}^{-2} \cdot \mathrm{H}^{-1} \cdot \mathrm{Bar}^{-1}\right)\end{array}$ & \\
\hline$\gamma-C D$ & $1,451.3$ & $0.67 \mathrm{mM}$ & $<1.2$ & $\mathrm{~N}$ & $575+-30$ & $20+-3$ \\
\hline$\gamma-\mathrm{CD} / \mathrm{Ad}$ & $1,451.3$ & $\begin{array}{l}0.67 \mathrm{Mm} \text { per } \\
3.3 \mathrm{mM}\end{array}$ & 1.2 & $\mathrm{~N}$ & $571+-25$ & $41+-2$ \\
\hline Rhodamine B & 479.01 & $1 \mathrm{mM}$ & $1.8 \times 1.4$ & + & $279+-20$ & $87+-3$ \\
\hline$\left[\mathrm{Fe}(\mathrm{CN})_{6}\right]^{3-}$ & 212.0 & $1.5 \mathrm{mM}$ & dia 0.9 & - & $585+-32$ & $36+-3$ \\
\hline EB & 960.8 & $15 \mu \mathrm{M}$ & $1.2 \times 3.1$ & - & $573+-28$ & $83+-1$ \\
\hline Cyt.c & 12,800 & $0.125 \mathrm{mg} \mathrm{ml}^{-1}$ & $2.5 \times 2.5 \times 3.7$ & - & $568+-55$ & $98+-1$ \\
\hline TMPyP & 678.8 & $0.75 \mu \mathrm{M}$ & $1.7 \times 1.7$ & + & $235+-18$ & $99+-1$ \\
\hline Gold particles & / & $\begin{array}{l}10^{12} \text { unit per } \\
\mathrm{ml}\end{array}$ & Diameter 5 & - & $593+-31$ & $100+-1$ \\
\hline
\end{tabular}

Meaning of symbols: Ad, adamantane; $\gamma$-CD, $\gamma$-cyclodextrin; cyt.c, cytochrome c; NSC, nanostrandchannelled; TMPyP, 5,10,15,20-tetrakis-(N-methyl-4-pyridyl)-21,23-H-porphyrin tetratosylate. Reproduced with permission from [50].

Research articles discussed above suggested that the membrane properties are dependent on the ionic charge of the test species used for filtration. In a very recent article, Joshi et al [52] studied the permeation of many species with different ionic charges. This article has a lot to differ and agree with other research papers discussed earlier. Joshi et al tested variety of solvents which are water based and non-water based to check the permeation through GO membranes, but they observed that only water based solutions are found to pass through the nanochannels of the GO membrane. Authors report that molecules dissolved in water can enter and move through the graphene capillaries until the physical size of ions or molecules exceeds the critical one which is approximately $4.5 \AA$. In their methodology, the GO membrane was transferred into a copper foil, glued and sealed in a Utube set-up as shown in Figure 12. Several salt solutions containing ions with different sizes were tested in order to check their permeation through GO membrane as function of size. In order to check permeation, authors adopted two methods. One being the qualitative is the in-situ monitoring the ion permeation through membrane by measuring the conductivity of permeates with time. In order to measure the transport of species from feed to permeate in quantitative Joshi et al performed chemical analysis for species present in both sides. Figure 12 shows the permeation as function of size of ionic or molecular species in their hydrated form. Figure 13 clearly shows a sharp cutoff for the rate of diffusion for the species large than the critical size of $\sim 4.5 \AA$. This report further gives the estimate of diffusion rate $J$ for the network of capillaries present inside the GO laminates. Authors used the classical diffusion equation

$I=D \times \Delta C \times A_{\text {eff }} / L_{\text {eff }}$ 
Where $D=10^{-5} \mathrm{~cm}^{2} / \mathrm{s}$ is the Diffusion Coefficient for small ions in water and $\Delta C$ is the concentration gradient across the membrane. For a 5 micron thick GO membrane with an area of $1 \mathrm{~cm}^{2}$, authors estimated an effective area $A_{\text {eff }}$ equal to $10^{-3} \mathrm{~cm}^{2}$ of the water column (effective length approximately $0.5 \mathrm{~cm}$ ) through which the diffusion can occur. Using these numbers, Joshi et al [52] found the diffusion coefficient value of $2 \times 10^{-3} \mathrm{mg} / \mathrm{h} / \mathrm{cm}^{2}$ which is 3000 times smaller than the measured rate. Furthermore, the authors reported that the ion permeability of the GO membrane is as high as that for a sheet of the standard filter paper. Authors also estimated the rejection rate, which is up to some extant similar to the reported value by others. In their work, the permeation depends only on size. No noticeable dependence of charge of the species on permeation was noticed. In order to support their model and mechanism, Joshi et al [52] performed molecular dynamics simulations to

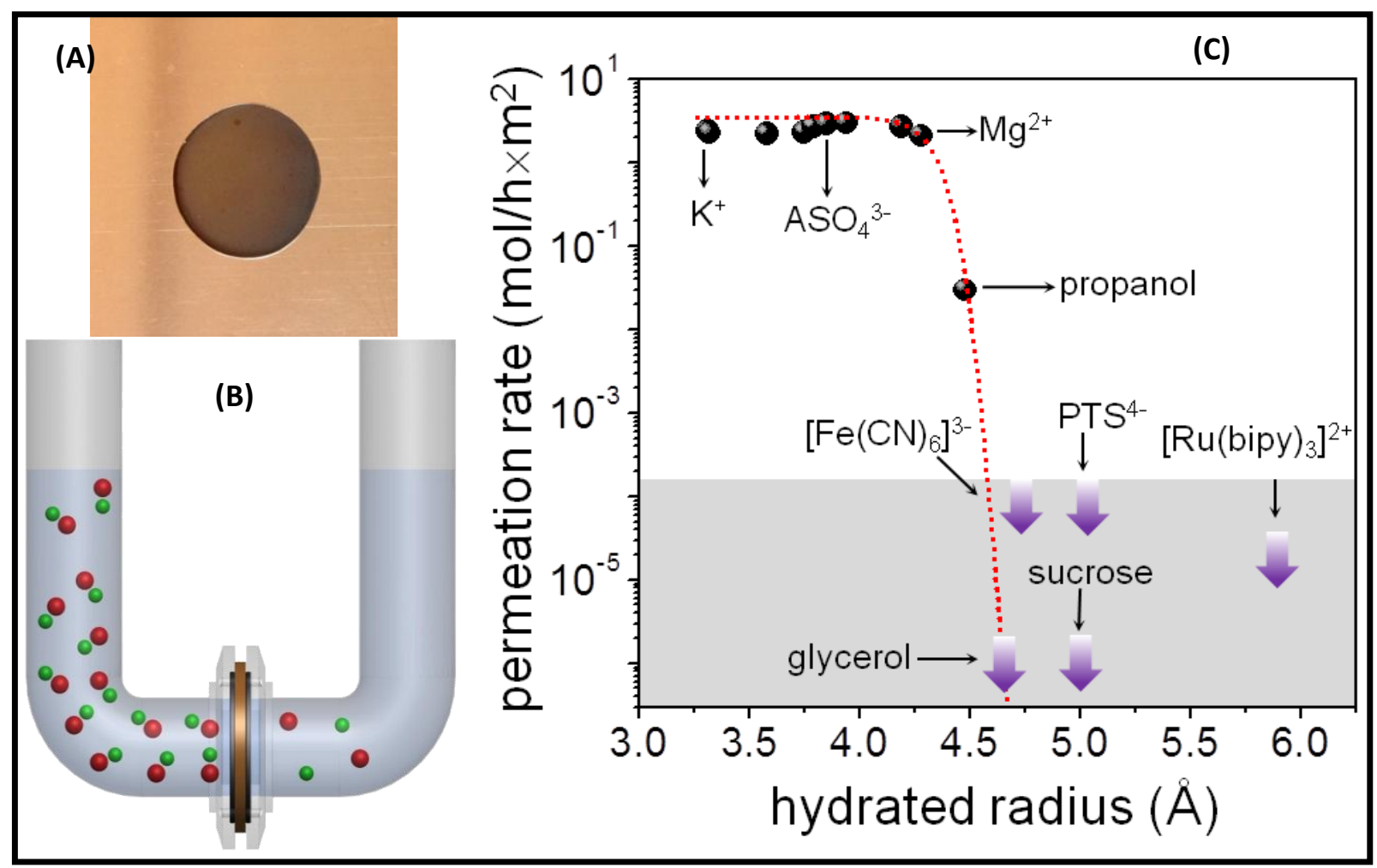

Figure 12 A) Photograph of the membrane glued on Cu foil. B) Schematic of the $U$ tube setup used for filtration experiment. C) Variation of permeation rate with hydrated radius of the species tested for filtration. Some species are named in the plot while other can be found in original article. Figure adopted with permission from [52].

understand the fast permeation. 
Figure 13 is the representative theoretical setup employed for simulations and the permeation results. For a brief explanation, Joshi et al [52] used two reservoirs for feed and

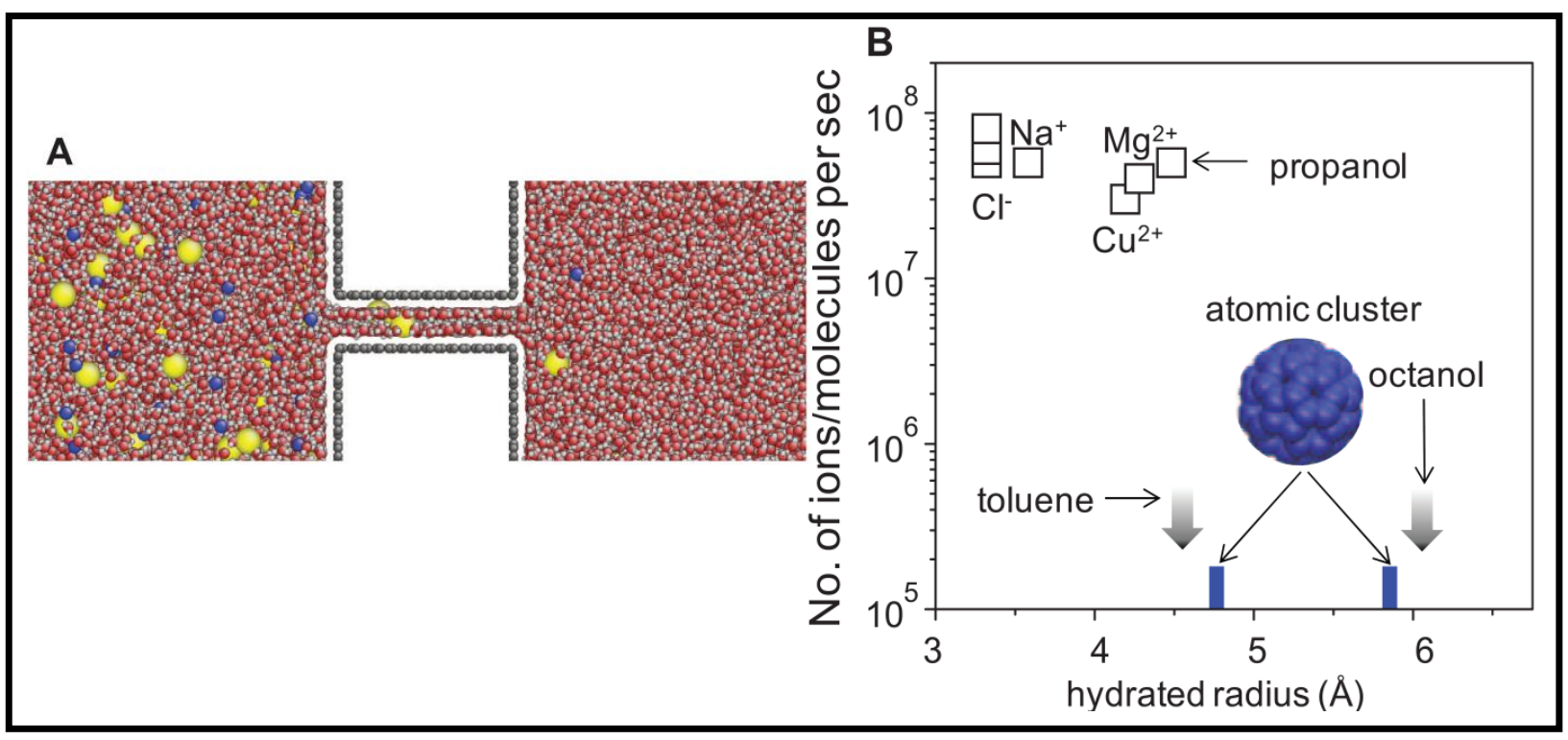

Figure 13.A) Schematic shows the theoretical set-up used to understand the transport phenomenon. B) Plot showing the permeation in terms of ions/ molecules per second as function of size of the species tested in our theoretical experiment. Figure adopted with permission from [52]

permeate, separated by graphene with a variation in width from 7 to $13 \AA$. Their model suggests that the graphene capillary can accommodate 2 layers of water molecules and also supports the cut-off at critical size around $\sim 4.5 \AA$.

Joshi et al [52] work was followed by some important reports on membrane application of

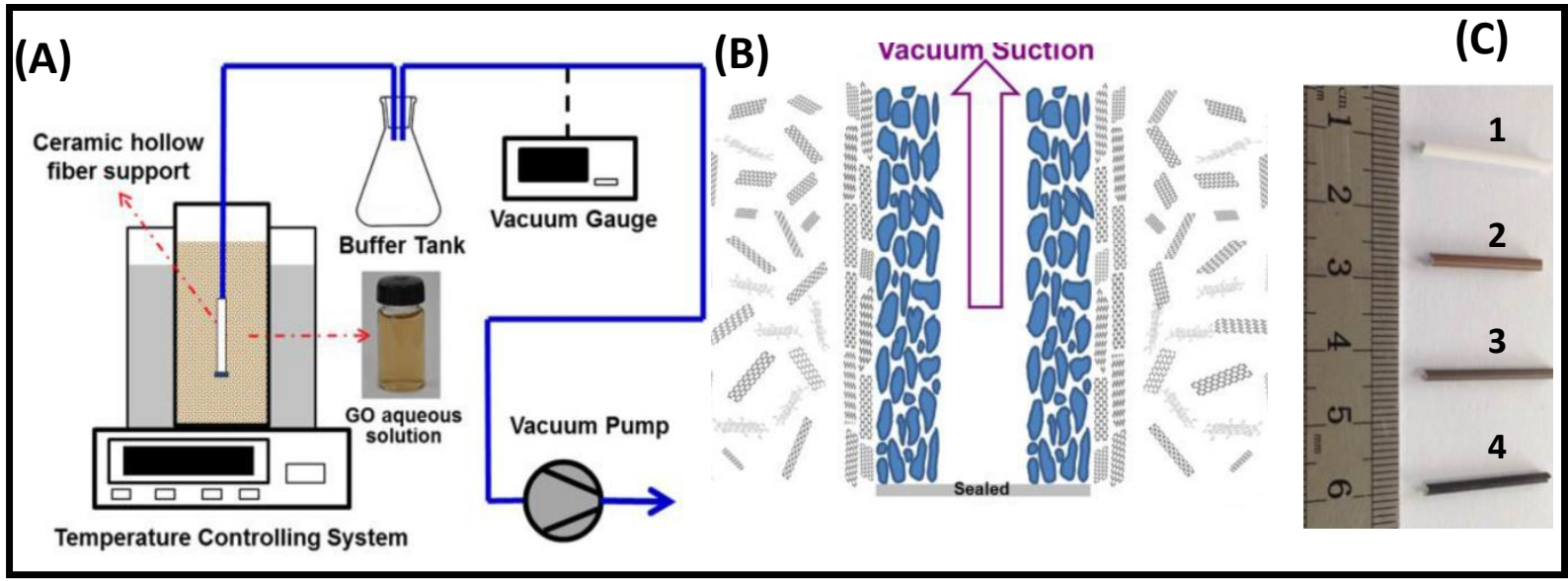

Figure 14. A) Schematic showing the synthesis procedure. B) Schematic of the vacuum suction process. C) Photographs of (1) blank ceramic hollow fiber and fiber coated with $\mathrm{GO}$ membrane with different thickness (2-4). Figure reproduced with permission from [53].

620-GO. For example, Huang et al [53] studied selective molecular separation of aqueous 
organic solution using GO membrane and is very interesting. Huang et al [53] have used a different approach to utilize the membrane properties of GOES. Readers must refer the original article for full technical details in order to understand their membrane preparation method. As evident from Figure 14, authors have coated the ceramic hollow support with GO to make a membrane structure by vacuum suction method according to the geometric configuration of the hollow fiber. Similar to the other vacuum filtration methods, the GO sheets stacks to the surface in the form of membrane with controlled thickness. Using such system, authors have measured the performance of the membrane to separate DMC/water mixture with three different concentrations limited to $3 \%$ feed water content to avoid the phase separation. Authors performed the permeation experiment at four different temperatures and observed that the total permeation flux increase linearly with temperature. Also, they have witnessed that the total permeation flux increases with increase in feed water content. Authors concluded that the high separating performance is

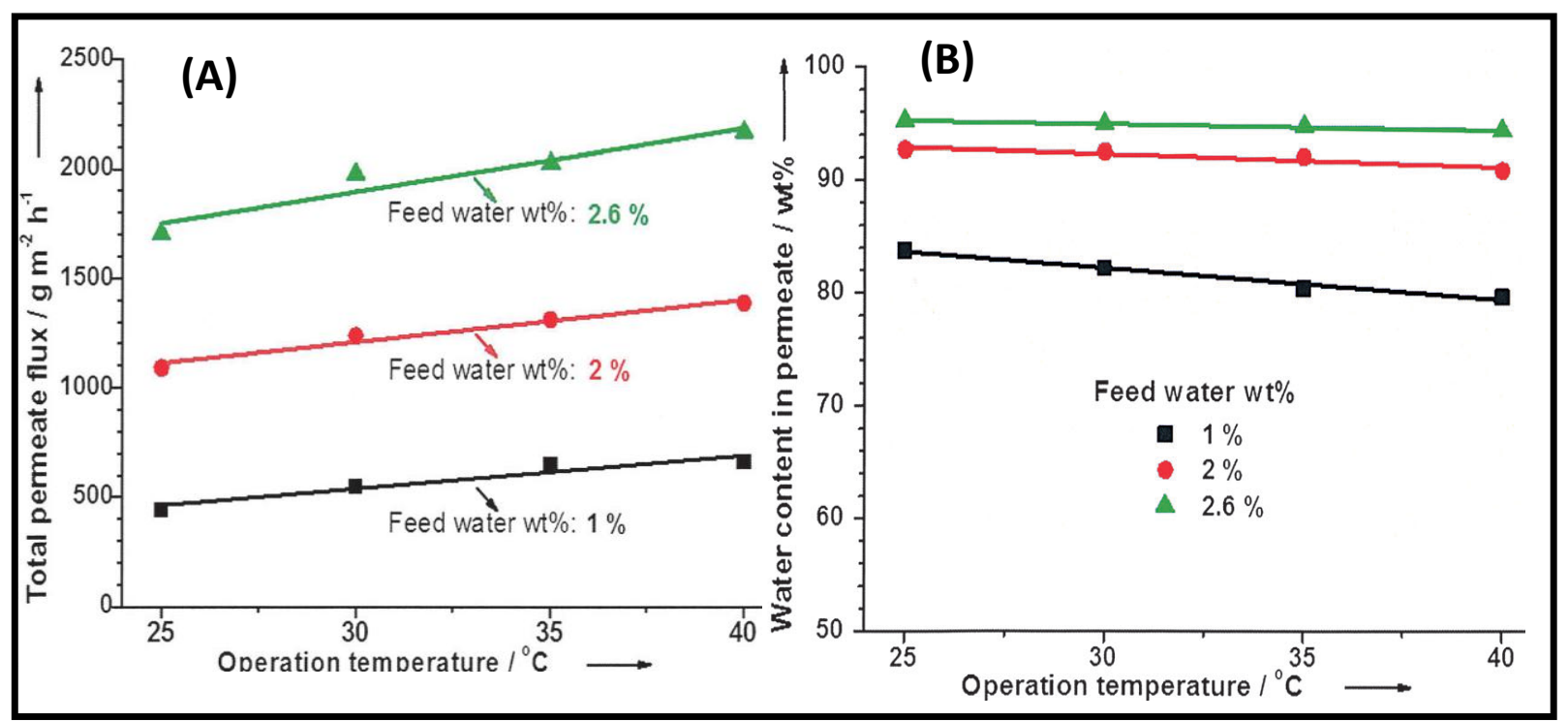

Figure 15. A) Variation of total permeation flux with temperature. B) Variation of water content in permeates as function of temperature. Figure adopted with permission from [53].

due to the preferential water sorption ability and fast water diffusivity in the GO capillaries, which very closely matches with the mechanism and models proposed by Geims's group $[37,52]$. 
In a very recent work, Gao et al [54] demonstrated the applicability of GO as proton exchange membrane for cell application. In order to perform the experiment, the authors have used ozonated GO and the resulting material has higher percentage of oxygenated functional group. The free standing ozonated GO films when tested for fuel cells application they showed improved proton conductivity at higher humidity. Figure 16 shows the ozonation, proton hoping in ozonated GO flake, conductivity as function of relative humidity and finally a schematic of the polymer electrolyte fuel cell with GO/ Ozonated GO

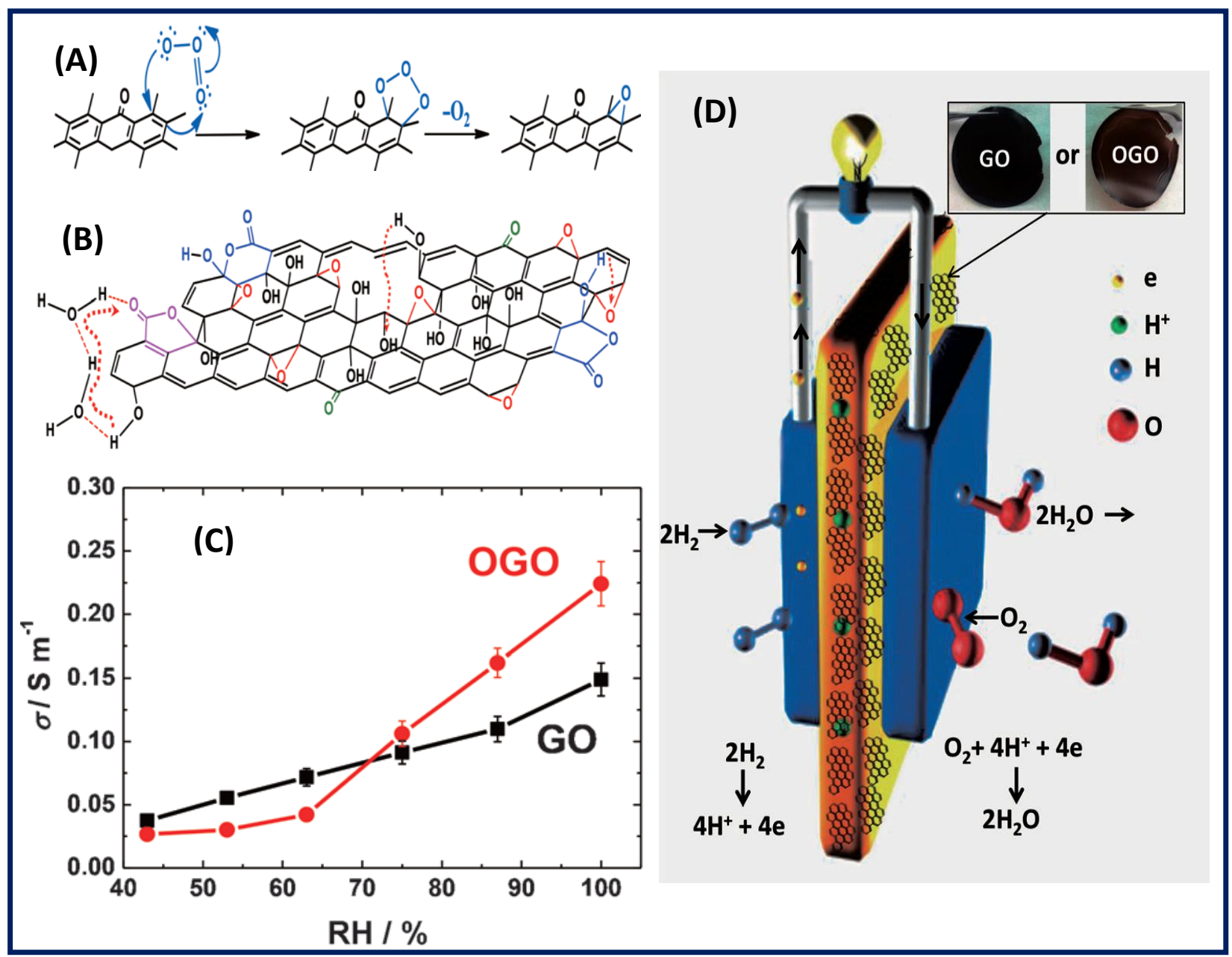

Figure 16. A) Schematic representing the process of ozonation as reaction between $\mathrm{O}_{3}$ molecules and GO basal plane. B) Schematic shows the path of proton hopping in ozonated GO flake. C) Variation of conductivity with relative humidity for GO and ozonated GO membranes. D) Schematic of the polymeric electrolyte fuel cell with GO/ozonoated GO, inset shows the photographs of GO and ozonated GO membrane. Figure reproduced with permission from [54].

membrane. Work by Gao et al [54] is certainly an important step towards implementing GO for fuel cell application. All the article cited above have shown the potential of GO for membrane application. 
Loh et al [55] employed the surface of water as a template and assembled the GO film on it by exploiting the amphiphilicity of GO films. Authors have cross linked the GO sheets with methacrylate to get a highly wrinkled membrane with enormous surface area. According to their report the cross-linking introduces several covalent linkages and enhances the in-plane stiffness. The highly wrinkled membrane obtained in this work has been employed to favour the rapid stem-cell differentiation towards bone cell lineage without the use of any other inducers. Such type of scalable GO membranes has futuristic applications in regenerative medicine. In another work, Rodrigues et al [56] has reported the usefulness of graphene oxide modified membranes for the removal of bacteria and their inactivation. Their experimental investigations carried out at these graphene oxide modified poly( $\mathrm{N}$-vinyl carbazole) membranes using E. Coli (Gram Positive) and B. Subtilis (Gram Negative) exhibited a greater antibacterial activity. The observed superior antibacterial activity of these modified membranes was due to the production of reactive oxygen species (ROS) which is capable of damaging the bacterial cell and hinders their metabolic activity which in turn inhibit the bacterial growth. From these observations, it was evident that these membranes are potential candidates for waste water treatment. In a recent work, Lee et al [57] demonstrated that the inclusion of graphene oxide membranes in to the membrane bioreactor suppress the fouling encountered during waste water treatment. Further, Lee et al [57] evidenced that the use of graphene oxide membrane overcame the fouling to a situation such that five fold lengthening time witnessed between the chemical cleanings. Moreover, it was very surprising to note that the inclusion of only 1 wt\% graphene oxide during the synthesis of membrane is highly efficient to result in a novel membrane that can exhibit excellent anti-fouling capability for membrane bioreactors. The inclusion of graphene oxide was found to alter the pore size, pore structure and surface charge of the membrane. Experiments also confirmed that these graphene oxide modified membranes also exhibited superior mechanical strength and excellent water flux. From all these superior characteristics, it is evident that these membranes are excellent candidates for desalination. Bano et al [58] reported a graphene blended polymer matrix for an efficient desalination application. More specifically, they have demonstrated a graphene oxide incorporated poly amide (PA) nanofiltration membrane with enhanced permeability, excellent selectivity and antifouling properties for an effective desalination. The improved flux associated with 
graphene oxide - PA membrane ( $0.2 \%$ graphene oxide membrane) was found to be twelve times better than with either PA alone or graphene oxide membrane itself. The effective desalination and the improved flux together with the observed antifouling property of this particular membrane were attributed to the improved hydrophilicity of the PA membrane that resulted due to the incorporation of graphene oxide. Recently, reduced graphene oxide/ $\mathrm{TiO}_{2}$ blended polyvinylidene fluoride membrane (PVDF) was reported by Safarpour et al [59]. The foretold membrane was synthesized using phase inversion technique. Results indicated that the inclusion of $0.05 \mathrm{wt} \%$ graphene oxide $/ \mathrm{TiO}_{2}$ exhibited excellent water flux (55\% increased water flux) and flux recovery ratio than bare PVDF. In addition to that, this graphene oxide- $\mathrm{TiO}_{2}$ blended PVDF membrane also exhibited excellent fouling resistance. The excellent fouling resistance and the hydrophilicity were attributed to the inclusion of graphene oxide with numerous oxygen terminated functional groups. Further, classical molecular dynamics calculations was performed by Nicolai et al [60] by considering the coupling observed between salt rejection and water permeability as a function of linker concentration, thickness and applied pressure. Based on the calculation, Nicolai et al [60] reported that water permeability in graphene oxide can be tuned from $5 \mathrm{~L} \mathrm{~cm}^{-2}$ day $^{-1} \mathrm{Mpa}^{-1}$ to $400 \mathrm{~L} \mathrm{~cm}^{-2} \mathrm{day}^{-1} \mathrm{Mpa}^{-1}$. Further, Nicolai et al [60] evidenced that such permeation follow $\mathrm{C}_{n} \mathrm{~h}^{-\alpha} \mathrm{n}$ law. The important observations made in this work were the following: (i) when the pore size remains the same, the water permeability can be increased by decreasing the spacing between the pores (ii) for a given spacing between the pores, the water permeability can be increased to two orders of magnitude by increasing the pore size (iii) a $100 \%$ salt rejection was witnessed for linker concentrations $n \leq 32$. From all these observations, it is evident that these types of graphene oxide membranes are suitable candidates for an effective desalination application. Moreover, Nicolai et al [60] calculations confirmed that under similar conditions of applied pressure and characteristics of membrane, it is expected that these graphene oxide membranes offer a perfect salt rejection coupled to a water permeability of about two orders of magnitude higher than any other existing reverse osmosis technology. Li et al [61] in their recent work reported carbon dots impregnated graphene oxide membrane as an effective tunable permeation system. According to Li et al [61], the purpose of embedding the carbon dots in the interspaces is to tune the spacing and channels that exist between graphene oxide layers. Further, $\mathrm{Li}$ et al [61] attributed that the compositional similarity between carbon dots and graphene oxide 
favoured a better distribution of carbon dots than any other nanomaterials on to the graphene oxide and thereby an excellent compatible permeation membrane has emerged. Results also confirmed that the permeation of the graphene oxide membrane from $18 \mathrm{~L} \mathrm{~h}^{-1}$ $\mathrm{m}^{-2}$ was increased to a whopping $204 \mathrm{~L} \mathrm{~h}^{-1} \mathrm{~m}^{-2}$ by embedding the carbon dots on to the graphene oxide membrane. The carbon dots embedded graphene oxide membrane have been also tested and found to be efficient towards removing organic pollutants.

\section{Conclusions and Future Prospective:}

Membranes that operate via the application of pressure were used in waste water treatment and in pharmaceuticals. In reality, a superior ultrafast membrane is expected to be extremely thin in order to have efficient (maximum) permeability and robust to tolerate the applied pressure. At present, there is an urgent need to develop speciality membrane that finds potential application in energy and environmental research. The speciality membranes to be developed for such application should exhibit maximum rejection rate and exceptional permeance. In practice, though there are several polymeric membranes that have been developed and reported for speciality applications, their permeation is very poor. Disadvantage of employing polymeric membranes for energy and environment applications is that they cannot withstand extreme temperatures and conditions such as strong acid, alkali or organic solvents [62-64]. All these above mentioned issues associated with polymeric membranes are the major cause for a growing demand to develop alternate membranes that will be used for energy and environment applications. On the other hand, owing to the excellent mechanical property, chemical inertness, availability of rich functional groups and environmental safety, carbon based materials are widely being researched for membrane applications. Initially, carbon nanotubes (CNTs) have been considered to be an excellent candidate for membrane applications due to their inherent 1D hollow structure with excellent mechanical strength. However, large scale assembly of highly dense vertical arrays of CNTs for membrane applications is really a very difficult task. Therefore, creation of CNT membranes remains only in theory and the practical implementation of this membrane may not be possible $[65,66]$. Later, amorphous carbon forms such as diamond like carbons have been attempted for membrane applications due to their exceptional mechanical hardness and chemical inertness $[67,68]$. However, their real time application is also very limited due to their high energy requirement and the 
equipment size [69]. Due to its excellent characteristics, we believe that $\mathrm{GO}$ is expected to be an outstanding material for membrane applications. Several research groups have reported the outstanding properties associated with graphene oxide membrane to support the versatile future of the GO membrane. Indeed, there are some agreement and disagreement on the observed results and the proposed transport mechanism. However, these can be clearly understood in the near future due to ongoing continuous efforts. Upon comparison with other membrane materials, GO membrane has a leading edge due to the ease of their preparation and processing, and provide uniform pore size distribution in membranes. Further, the structure of the GO membranes can be modified to tailor the pore size or the interlayer spicing between the GO layers to utilize such membranes for real applications.

Acknowledgement: RKJ express his deep sense of gratitude towards Prof. Andre Geim and Dr. Rahul Nair of the University of Manchester. Prof Geim introduced him to this very interesting field of research and Dr. Nair helped him throughout his training in membrane science and technology during Marie Curie International Incoming fellowship at the University of Manchester, U.K. RKJ acknowledge the faculty start up grant support from MSE at UNSW. SA acknowledges DST-SERB for the grant GAP 03/2014 under fast track scheme.

Author contributions: RKJ proposed the content of this review together with YN, VS and MY. YN and SA wrote some sections of the manuscript. VS and MY took part discussions and added some sections in this manuscript. All authors have reviewed the manuscript.

Additional information: The authors declare no competing financial interests. 


\section{References}

1 Zhao, C., Nie, S., Tang, M. \& Sung, S. Polymeric pH-sensitive membranes - A review. Prog. Polym. Sci. 36, 1499-1520 (2011).

2 Ulbricht, M. Advanced functional polymer membranes. Polymer 47, 2217-2261 (2011).

3 Shao, P. \& Haung, R.Y.M. Polymeric membrane pervaporation. J. Membr. Sci. 287, 162179 (2007).

4 Laberty-Robert, C., Vallé, K., Pereira, F. \& Sanchez, C. Design and properties of hybrid organic-inorganic membranes for fuel cells. Chem. Soc. Rev. 40, 961-1005 (2011).

5 Yampolskii, Y. Polymeric gas separation molecules. Macromol. 45, 3298-3311 (2012).

6 DeVos, R.M. \& Verweij, H. High selectivity, high flux silica membrane for gas separation. Science 13, 1710-1711 (2011).

7 Verweij, H. Inorganic Membranes. Curr. Opinion in Chem. Eng. 1, 156-162 (2012).

8 Cot, L., Ayral, A., Durand, J., Guizard, C., Hovnanian, N. \& Julbe, A. Inorganic membranes and solid state sciences. Solid State Sci. 2, 313-334 (2000).

9 Titus, M.P. Porous inorganic membranes for $\mathrm{CO}_{2}$ capture: Present and prospects. Chem. Rev. 114, 1413-1492 (2014).

10 Chen, X., Khoo, K.G., Kim, M.W. \& Hong, L. Deriving a $\mathrm{CO}_{2}$ - permselective carbon membrane from a multilayered matrix of polyion complexes. ACS Appl. Mater. Interf. 6, 10220-10230 (2014).

11 Yeo, Z.Y., Chew, T.L., Zhu, P.W., Mohamed, A.P. \& Chai, S.P. Synthesis and performance of microporous inorganic membranes for $\mathrm{CO}_{2}$ removal from natural gas - A Review. J. Porous. Mater. 12, 1457-1475 (2013).

12 Lulianelli, A. \& Basile, A. Hydrogen production from ethanol via inorganic membrane reactors technology: A Review. Catal. Sci. Technol. 1, 366-379 (2011).

13 Ward, T.L. \& Dao, T. Model of hydrogen permeation behaviour in palladium membranes. J. Membr. Sci. 153, 211-231 (1999).

14 Zhang, F., Zhang, W.B., Shi, Z., Wang, D., Jin, J. \& Jiang, L. Nanowire-Haired inorganic membrane with superhydrophilicity and underwater ultralow adhesive superoleophobicity for high-efficiency oil water separation. Adv. Mater. 25, 4192-4198 (2013).

15 McLeary, E.E., Jansen, J.C. \& Kapteijn, F. Zeolite based films, membranes and membrane reactors: Progress and prospects. Microporous and Mesoporous Mater. 90, 198-220 (2006).

16 Li, S., Wang, X., Beving, D., Chen, Z. \& Yan, Y. Molecular Sieving in a nanoporous boriented pure-silica-Zeolite MFI monocrystal film. J. Am. Chem. Soc. 126, 4122-4123 (2004).

17 Li, L., Dong, J., Nenoff, T.M. \& Lee, R. Desalination by reverse osmosis using MFI Zeolite membranes. J. Membr. Sci. 234, 401-404 (2004).

18 Li, L., Liu, N., McPherson, B. \& Lee, R. Influence of counter ions on the reverse osmosis through MFI zeolite membranes: implications for produced water desalination. Desalination 228, 217-225 (2008).

19 Severance, M., Wang, B., Ramasubramanian, K., Zhao, L., Winston Ho, U.S \& Dutta P.K. Rapid crystallization of Faujasitic zeolites. Langmuir 30, 6929-6937 (2014). 
20 Caro, J. \& Noack, M. Zeolite membranes: Recent developments and progress, Microporous and Mesoporous Mater. 115, 215-233 (2008).

21 Fornasiero, F., Park, H.G., Holt, J.K., Stadermann, M., Grigoropoulos, C.P., Noy, A. \& Bakajin, O. Ion exclusion by sub-2-nm carbon nanotube pores. Proc. Natl. Acad. Sci. 105, 17250-17255 (2008).

22 Hinds, B.J., Chopra, N., Rantell, T., Andrews, R., Gavalas, V. \& Bachas, L.G. Aligned multiwalled carbon nanotube membranes. Science 303, 62-65 (2004).

23 Majumder, M., Chopra, N. \& Hinds, B.J. Effect of tip functionalization on transport through vertically oriented carbon nanotube membranes. J. Am. Chem. Soc. 127, 90629070 (2005).

24 Holt, J.K., Park, H.G., Wang, Y., Stadermann, M., Artyukhin, A.B., Grigoropoulos, C.P., Noy, A. \& Bakajin, O. Fast mass transport through sub-2-nanometer carbon nanotubes. Science 312, 1034-1037 (2006).

25 Kar, S., Bindal, R.C. \& Tewari, P.K. Carbon nanotube membranes for desalination and water purification: Challenges and Opportunities. Nanotoday 7, 385-389 (2012).

26 Das, R., Ali M.E., Hamid, S.B.A., Ramakrishna, S. \& Chowdhury, Z.Z. Carbon nanotube membranes for water purification: A bright future in water desalination. Desalination 336, 97-109 (2014).

27 Kalra, A., Garde, S. \& Hummer, G. Osmatic water transport through carbon nanotube membrane. Proc. Natl. Acad. Sci. 100, 10175-10180 (2003).

28 Verweij, H., Schillo, M.C. \& Li, J. Fast mass transport through carbon nanotube membranes. Small 3, 1996-2004 (2007).

29 Corry, B. Designing carbon nanotube membranes for efficient water desalination. J. Phys. Chem. B. 112, 1427-1434 (2008).

30 Linds, B. Dramatic transport properties of carbon nanotube membranes for a robust protein channel mimetic platform. Curr. Opi. Solid State and Mater. Sci. 16, 1-9 (2012).

31 Goh, K., Setiawan, L., Wei, L., Jiang, W., Wang, R. \& Chen, Y. Fabrication of novel functionalized multi-walled carbon nanotube immobilized hollow fiber membranes for enhanced performance in forward osmosis process. J. Membr. Sci. 446, 244-255 (2003).

32 Jirage, K.B., Hulteen, J.C. \& Martin, C.R. Nanotuble - based molecular-filtration membranes, Science 278, 655-658 (1997).

33 Boutilier, M.S.H., Sun, C., O'Hern, S.C., Au H., Hadjiconstantinou, N.G. \& Karnik, R. Implications of permeations through intrinsic defects in graphene on the design of defect-tolerant membranes for gas separation. ACS Nano 8, 841-849 (2014).

34 O'Hern, S.C., Boutilier, M.S.H., Idrobo, J.C., Song, Y., Kong, J., Laoui, T., Atieh, M. \& Karnik, R. Selective ionic transport through tunable sub-nanometer pores in single-layer graphene membranes. Nano Lett. 14, 1234-1241 (2014).

35 Han, Y., Xu, Z. \& Gao, C. Ultrathin graphene nanofiltration membrane for water purification. Adv. Funct. Mater. 23, 3693-3700 (2013).

36 Titov, A.V., Kral, P. \& Pearson, R. Sandwiched graphene-membrane supercapacitors. ACS Nano 4, (2009) 229-234.

37 Nair, R.R., Wu, H.A., Jayaram, N., Grigorieva, I.V. \& Geim, A.K. Unimpeded permeation of water through helium leak-tight graphene based membranes. Science 335, 442-444 (2012).

38 Hummers Jr, W.S. \& Offeman, R.E. Preparation of Graphitic Oxide. J. Am. Chem. Soc. 80, 1339-1339 (1958). 
39 Dreyer, D.R., Park, S., C.W. Bielawski, R.S. Ruoff, The Chemistry of graphene oxide. Chem. Soc. Rev. 39 (2010) 228-240.

40 Zhu, Y., Murali, S., Cai, W., Li, X., Suk, J.W., Potts, J.R. \& Ruoff, R.S. Graphene and Graphene Oxide: Synthesis, Properties and Applications. Adv. Mater. 22, 3906-3924 (2010).

41 Kosynkin, D., Higginbotham, A., Sinitskii, A., Lomeda, J., Dimiev, A., Price, K. \& Tour, J.M. Longitudinal unzipping of carbon nanotubes to form graphene nanoribbons. Nature 458, 872-876 (2009).

42 Dikin, D.A., Stankovich, S., Zimney, E.J., Piner, R.D., Dommett, G.H.B., Evmeneko, G., Nguyen, S.T. \& Ruoff, R.F. Preparation and characterization of graphene oxide paper. Nature 448, 457-460 (2007).

43 Marcano, D.C., Kosynkin, D.V., Berlin, J.M., Sinitskii, A., Sun, Z., Slesarev, A., et al, Improved synthesis of graphene oxide. ACS Nano 4, 4806-4810 (2010).

44 Kim, H.W., Yoon, H.W., Yoon, S.M., Yoo, B.M., Ahn, B.K., Cho Y.H., Shin, H.J., Yang, H., Paik, U., Kwon, S., Choi, J-Y. \& Park, H.B. Selective gas transport through few-layered graphene and graphene oxide membranes. Science 34, 91-95 (2013).

45 Zhang, J., Xu, Z., Mai, W., Min, C., Zhou, B., Shan, M., Li, Y., Yang, C., Wang, Z. \& Qian, X. Improved hydrophilicity, permeability, antifouling and mechanical performance of PVDF composite ultrafiltration membranes tailored by oxidized low-dimensional carbon nanomaterials. J. Mater. Chem. A, 1, 3101-3111 (2013).

46 Li, H., Song, Z., Zhang, X., Huang, Y., Li, S., Mao, Y. et al. Ultrathin molecular sieving graphene oxide membrane for selective hydrogen separation. Science 4, 95-98 (2013).

47 Schrier, J. Carbon dioxide separation with a two-dimensional polymer membrane. ACS Applied Mater. Inter. 4, 3745-3752 (2012).

48 Sun, P., Zhu, M., Wang, K., Zhong, M., Wei, J., Wu, D., Xu, Z. \& Zhu, H. Selective ion penetration of graphene oxide membrane. ACS Nano 7, 428-437 (2013).

49 Huang, H., Miao, Y., Ying, Y., Liu, Y., Sun, L. \& Peng, X. Salt concentration, pH and pressure controlled separation of small molecules through lamellar graphene membranes. Chem. Commun. 49, 5963-5965 (2013).

$50 \mathrm{Hu}, \mathrm{M}$. \& Mi, B. Enabling graphene oxide nanosheets as water separation membranes. Environ.Sci.Technol. 47, 3715-3723 (2013).

51 Huang, H., Song, Z., Wei, N., Shi, L., Mao, Y., Ying, Y., Sun, L., Xu, Z. \& Peng, X. Ultrafast viscous water flow through nanostrand-channeled graphene oxide membranes. Nature Commun. 4, 3979-3979 (2013).

52 Joshi, R.K., Carbone, P., Wang, F.C., Kravets, V.G., Su, Y., Grigorieva, I.V., Wu, H.A., Geim, A.K. \& Nair, R.K. Precise and Ultrafast molecular sieving through graphene oxide membrane. Science 343, 752-754 (2014).

53 Huang, K., Liu, G., Lou, Y., Dong, Z., Shen, J. \& Jin, W. A graphene oxide membrane with highly selective molecular separation of aqueous organic solution. Angew. Chem. 53, 6929-6932 (2014).

54 Gao, W., Wu, G., Janicke, M.T., Cullen, D.A., Mukundan, R., Baldwin, J.K. et al. Ozonated graphene oxide film as a proton-exchange membrane. Angew. Chem. 53, 3588-3593 (2014).

55 Tang, L.A., Lee, W.C., Shi, H., Wong,E.Y., Sadovoy, A., Gorelik, S. et al. Highly wrinkled cross-linked graphene-oxide membranes for biological applications. Small 8, 423-431 (2012). 
56 Musico, Y.L.F., Santos, C.M., Dalida, M.L.P. \& Rodrigues, D.F. Surface modification of membrane filters using graphene and graphene oxide based nanomaterials for bacterial inactivation and removal. ACS Sustainable Chem. Eng. 2, 1559-1565 (2014).

57 Lee, J., Chae, H-R., Won, Y.J., Lee, K., Lee C-H., Lee H.H., Kim, I-C. \& Lee J.M. Graphene oxide nanoplatelets composite membrane with hydrophilic and antifouling properties for waste water treatment. J. Membrane. Sci. 448, 223-230 (2013).

58 Bano, S., Mahmood, A., Kim, S-J. \& Lee, K.H. Graphene Oxide modified polyamide nanofiltration membrane with improved flux and antifouling properties. J. Mater. Chem. A 3, 2065-2071 (2015).

59 Safarpour, M., Khatee, A. \& Vatanpour, V. Preparation of novel polyvinylidene ultrafiltration membrane modified with reduced graphene oxide/titanium-dioxide nanocomposite with enhanced hydrophilicity and antifouling properties. Ind. Eng. Chem. Res. 53, 13370-13382 (2014).

60 Nicolai, A., Sumpter, B.G. \& Meunier, V. Tunable water desalination across graphene oxide framework membrane. Phys.Chem.Chem. Phys. 16, 8646-8654 (2014).

61 Wang, W., Eftekhari, E., Zhu, G., Zhang, X., Yan, Z. \& Li, Q. Chem. Comm.50, 1308913092.

62 Van der Bruggen, B., Manttari, M. \& Nystrom, M. Drawbacks of applying nanofiltration and how to avoid them: A review. Sep. Purif. Technol. 63, 251-253 (2008).

63 Ulbricht, M. Advanced Functional polymer membranes. Polymer 47, 2217-2262 (2006).

64 Mulder, M. Basic Principles of Membrane Technology Second Edition, Kluwer Academic Pub, 1996.

65 Majumdar, M., Chopra, N. \& Hinds B.J. Mass transport through carbon nanotube membranes in three different regimes: ionic diffusion and gas and liquid flow. ACS Nano 5, 3867-3877 (2011).

66 Li, S., Li, H., Wang, X., Song, Y., Liu, Y., Jiang, L. \& Zhu. D. Super hydrophobicity of large area honeycomb like aligned carbon nanotubes. J. Phys.Chem. B 106, 9274-9276 (2002).

67 Karan, S., Samitsu, S., Peng, X., Kurashima, K. \& Ichinose, I. Ultrafast viscous permeation of organic solvents through diamond like carbon nanosheets. Science 335 444-447 (2012).

68 Paul, D.R. Creating new types of carbon-based membranes. Science 335 413-414 (2012).

69 Robertson, J. Diamond like amorphous carbon. Mater.Sci.Eng.Rev. 37 129-281 (2002). 